\title{
Eco-Friendly Protective Coating to Extend the Life of Art-Works and Structures Made in Porous Stone Materials
}

\author{
Mariateresa Lettieri $^{1}$ (D), Maurizio Masieri ${ }^{2}$, Marika Aquaro ${ }^{3}$, Debora Dilorenzo ${ }^{3}$ and Mariaenrica Frigione $^{3, *(D)}$ \\ 1 CNR-SPIN, SuPerconducting and Other INnovative Materials and Devices Institute, \\ Via Giovanni Paolo II 132, Fisciano, 84084 Salerno, Italy; mariateresa.lettieri@cnr.it \\ 2 CNR-ISPC, Istituto di Scienze del Patrimonio Culturale, Prov.le Lecce-Monteroni, 73100 Lecce, Italy; \\ maurizio.masieri@cnr.it \\ 3 Department of Innovation Engineering, University of Salento, Prov.le Lecce-Monteroni, 73100 Lecce, Italy; \\ aquaro.marika@gmail.com (M.A.); dilorenzo.debora@hotmail.it (D.D.) \\ * Correspondence: mariaenrica.frigione@unisalento.it; Tel.: +39-0832-297-215
}

Citation: Lettieri, M.; Masieri, M.; Aquaro, M.; Dilorenzo, D.; Frigione, M. Eco-Friendly Protective Coating to Extend the Life of Art-Works and Structures Made in Porous Stone Materials. Coatings 2021, 11, 1270. https://doi.org/10.3390/coatings11111270

Academic Editor: Alessandro Pezzella

Received: 24 September 2021

Accepted: 18 October 2021

Published: 20 October 2021

Publisher's Note: MDPI stays neutral with regard to jurisdictional claims in published maps and institutional affiliations.

Copyright: (c) 2021 by the authors. Licensee MDPI, Basel, Switzerland. This article is an open access article distributed under the terms and conditions of the Creative Commons Attribution (CC BY) license (https:// creativecommons.org/licenses/by/ $4.0 /)$
Abstract: The application of hydrophobic treatments to stone surfaces is the most common proven method to prevent, or at least limit, the degradation of stone-made constructions and artworks brought about by the ingress and action of water, in particular in the case of very porous stone materials. To avoid the use of protective products containing harmful solvents, new green products have been proposed. In this paper, an eco-friendly hydrophobic coating, based on a fluorine polymer dispersed in water, was deeply analyzed to evaluate its protective properties, especially for very porous stone substrates. To this aim, a wide characterization of treated and untreated Lecce stone elements, i.e., a stone typical of the Apulia region, was carried out to assess the optimum required amount, the effectiveness and the protective capability, even against graffiti staining, of the green hydrophobic treatment, still allowing the stone to retain adequate vapor permeability. The efficacy of the eco-friendly product was analyzed also after a short time (four weeks) of outdoor exposure. Suitable performance and short-term durability of the green hydrophobic coating were found, comparable or even greater than those reported in the current literature for other widespread commercial products, confirming the capability of the product to preserve porous stone surfaces even in absence of solvents in its formulation. The study also allowed to experiment with the "contact sponge" test as an appropriate method for evaluating the water absorption properties of the stone.

Keywords: stone protection; cultural heritage; eco-friendly protectives; hydrophobic treatments; anti-graffiti; multifunctional coatings

\section{Introduction}

Porous stone materials, such as Lecce stone, Noto stone, Globigerina stone, Ançã stone, Tuffeau limestone, Maastricht limestone, have been widely employed since ancient times to realize buildings, monuments, ornaments and other works of art, in UNESCO World Heritage sites [1], in many European countries [2] and particularly in the Mediterranean regions (such as the southern Apulia [3], Sicily [4], and Malta [5]). Their characteristic high porosity makes them suitable for being worked and modeled to create true masterpieces; this feature is, at the same time, responsible for their high vulnerability towards environmental agents, foremost water; consequently, they can easily undergo degradation which compromises their mechanical characteristics, functionality and external appearance.

Water can easily penetrate porous stones either in liquid or vapor forms, it can contain soluble salts, it can change its physical state according to the external temperature: all these processes are particularly damaging to the porous materials and determine their limited durability over time, especially if the stone is outdoor exposed. Therefore, the need arises to protect the stone-made historical buildings and artworks, also to preserve the Cultural Heritage, representing the local history, culture and traditions, for future generations. 
Preservation and conservation procedures must be, then, carried out employing appropriate materials and technologies that take into account the level of conservation/degradation of the stone, the conditions of exposure, the function of the stone element. The use of such protective materials also allows limiting restoration/maintenance interventions, or even the demolition of a building, with the necessity to rebuild it, with obvious savings in terms of time, costs and material resources. The use of protective/conservative treatments, therefore, represents also an advantage from a sustainability point of view.

Coating materials are frequently applied on the surface of the stone for its protection against the action of aggressive environments. The main function of a protective coating is, in fact, to prohibit or at least limiting the entrance of water, even in presence of soluble salts or acid substances, into the material. The coatings must also allow the breathing of the protected stone; they must not alter the color and appearance of the stone; they must be as much as possible harmless to the environment and to humans.

The commercial treatments commonly used are based on solvents. The solution, formed by the polymer dissolved in the proper solvent, is placed on the substrate that needs protection, and the film formation takes place by evaporation of the solvent. This procedure assures a good penetration of the protective agent even into the smaller pores of the substrate. The use of solvents in protective treatments, on the other side, raises severe concerns for operators and for people who come into contact with the treated surfaces, as well as for the environment where the solvent will evaporate.

A recent challenge in the formulation of coatings is to eliminate any Volatile Organic Compounds (VOC) in the product's composition to reduce the potential harmful effects for the environment and the users' health. With this aim, coatings have been obtained gradually moving from solvent-based products with high VOC contents to low or zero VOC water-based systems [6]. To avoid the use of harmful solvents, various solutions of green treatments have been recently proposed for applications in the architectural and building sectors [7] such as waterborne protectives exhibiting suitable hydrophobicity [8] and good stability to the environmental agents [9], organic-inorganic free solvent products able to give rise to highly hydrophobic [10] and highly transparent coatings [11], polymers extracted from natural sources (such as poly-lactic acid (PLA) [12] and plant proteins (zein) [13]). However, in some cases, such coatings (e.g., the waterborne ones) did not attain satisfactory properties and performance, in particular with regard to film formation [14], viscosity [15], and water absorption [16]. On the other hand, to the best of our knowledge, it has not yet been proven that these products are also effective as anti-graffiti protection. Furthermore, only in a few studies has their durability been assessed.

In the last years, the authors of this paper have established a fruitful collaboration to propose effective solutions to the exposed problems [17], also by testing new products suitable for stone materials with different porosity [18] and as anti-graffiti systems [19] and proposing new testing methods [20]. In this paper, a green protective product has been tested when applied to a highly porous stone characteristic of the south area of Apulia region, i.e., Lecce Stone. A complete characterization of the treated and untreated stone elements was carried out in order to assess the efficacy of the eco-friendly product to protect and, therefore, to extend the life of the stone elements. The durability of the surface treatment was, finally, investigated after a short-time outdoor exposure. This study represents the first stage of a wider investigation aimed at assessing the performance and long-term durability characteristics of the eco-sustainable protective product, even as anti-graffiti protection for the stone substrate.

\section{Materials and Methods}

\subsection{Materials: Protective Product and Stone Substrate}

A green commercial product, i.e., free from volatile organic compounds (VOC), consisting of a fluorine-based polymer dispersed in water (trademark PROTECT IT R 100/HBG, provided by IBIX s.r.l., Santa Maria in Fabriago, Ravenna, Italy), was applied to a stone substrate. This system is able to generate oleo/hydrophobic coatings and it is suggested 
for the protection of absorptive porous materials. The product is especially recommended for the treatment of valuable stone surfaces and architectonic elements; it can be applied to both vertical and horizontal surfaces, without further dilution. The supplied product is a transparent colorless liquid (Figure 1a) and, as reported in the technical data sheet [21], its density is $1.0 \mathrm{~kg} / \mathrm{L}$ at $25^{\circ} \mathrm{C}$.

\section{Protection}

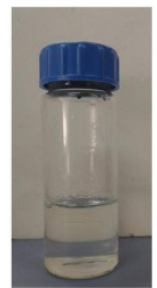

(a)

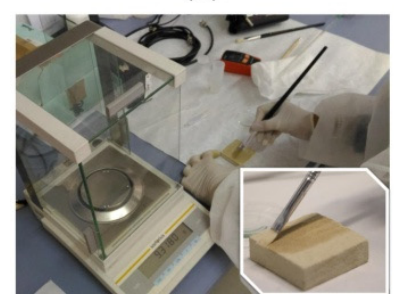

(d)
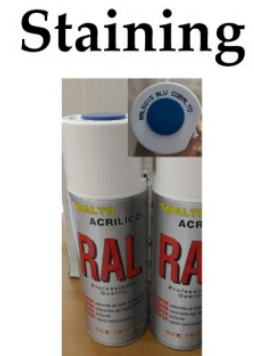

(b)

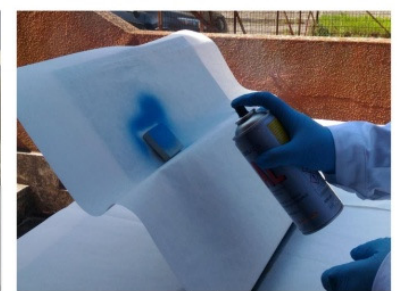

(e)
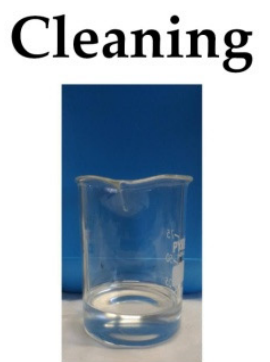

(c)

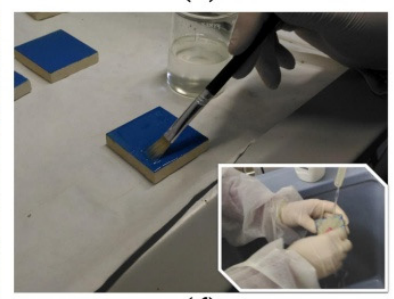

(f)

\section{Outdoor exposure}
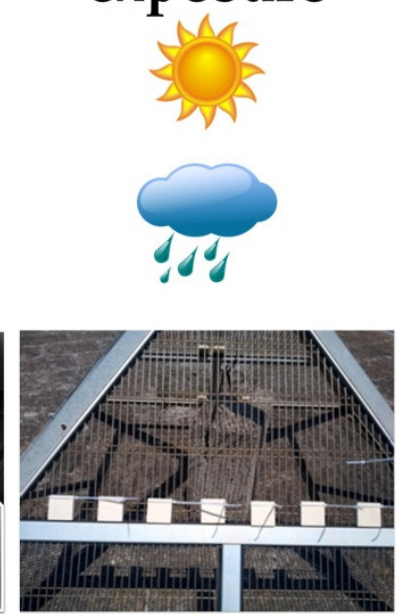

(g)

Figure 1. Materials and treatments: (a) Liquid fluorine-based polymer for stone protection; (b) Spray cans of acrylic paint; (c) Chemical remover for graffiti cleaning; (d) Set-up for the application of the coating and detail of brushing on a specimen of Lecce stone; (e) Staining by the blue-colored paint; (f) Application of the chemical remover and subsequent rinsing by running tap water and a sponge; (g) Stone specimens during the outdoor exposure.

A fluorine-based system was chosen since such chemical products are considered excellent protective agents and are among the most widely used materials for stone protection. Coatings obtained from fluorinated polymers typically exhibit both high hydrophobic properties [22] and anti-graffiti protection [23]; being the C-F bond a strong chemical bond, good durability and chemical stability are also expected and observed [24].

A highly porous calcarenite, named "Lecce stone", was chosen as the substrate to test the protective product. This natural stone material originates from quarries located in the Salento region (Apulia, southeastern Italy), specifically near the city of Lecce (hence the name "Lecce stone"). Typical of Baroque architecture, "Lecce stone" has been employed in the built heritage in this area since ancient times. Still widely used in many historic and civil buildings, this material has known an increasing diffusion also out of Italy as a decorative dimension stone. Besides, due to its characteristics, "Lecce stone" can be regarded as a reference of porous materials used for monumental heritage and civil buildings in many European countries. Noto stone in Sicily [25], Globigerina limestone in Malta [26], Tuffeau limestone in the Loire Valley (France) [27], Maastricht limestone in northern Europe [28], Ançã stone in Portugal [29] are some examples of stone materials similar to "Lecce stone" for both features and processes of decay.

"Lecce stone" is composed of calcite as the main constituent (93-97\% [30]), very small quantities of clay and phosphates [31], as well as other non-carbonate minerals [32]. "Lecce stone" is frequently affected by deterioration phenomena (such as alveolization, erosion, rising damp, salt crystallization), in which water is the factor causing most of the processes of decay. The specimens of "Lecce stone" used in this study exhibited a porosity of $42 \%$ with an average pore radius of $1.23 \mu \mathrm{m}$ and pore sizes mainly between 0.5 and $4 \mu \mathrm{m}$, as evaluated by Mercury Intrusion Porosimetry [20].

Prismatic stone specimens, with dimensions of $5 \times 5 \times 1 \mathrm{~cm}^{3}$, were cut by a saw from quarry blocks. Following the UNI10921 standard protocol [33], the specimens were smoothed with abrasive paper (180-grit silicon carbide), numbered using an engraver tool, 
washed with deionized water and cleaned with a brush in order to remove dust deposits. The stone specimens were left $24 \mathrm{~h}$ in the laboratory, at a temperature of $23 \pm 2{ }^{\circ} \mathrm{C}$ and relative humidity (R.H.) of $45 \pm 5 \%$; then, they were completely dried in an oven at $60{ }^{\circ} \mathrm{C}$, until the dry weight was achieved. Finally, the samples were stored in a desiccator with silica gel (R.H. $=15 \%)$ at $23 \pm 2{ }^{\circ} \mathrm{C}$.

A commercial acrylic spray paint (Cilvani RAL by Cilvani S.r.l., Caivano, Italy), bluecolored (RAL code 5015), provided in a pressurized can (Figure 1b), was used as the staining agent.

The removal of the paint was, then, performed using a commercial chemical remover (trademark ECO 7 G, provided by C.I.R. Chimica Italiana Restauri, Arezzo, Italy) formulated for graffiti removal on stone materials, also for monuments and historic buildings. This remover, ready-to-use, is a mixture of esters, surfactants, and emulsifiers; it does not contain chlorinated solvents, all its components are declared as biodegradable. The remover is a transparent gel (Figure 1c) having a density of $1.02 \mathrm{~kg} / \mathrm{L}$; it can be applied by either brush or paint roller. The time of action should range between $10 \mathrm{~min}$ and $12 \mathrm{~h}$, depending on both the porosity of the substrate and the staining agent.

\subsection{Application of the Protective Product and Experimental Investigations}

\subsubsection{Surface Protection}

The first stage of the research was aimed at assessing the optimal quantity of protective product to apply on "Lecce stone". Starting from the amounts suggested in the technical data sheet for porous natural stone materials (i.e., $2-5 \mathrm{~m}^{2} / \mathrm{L}$ ), four different quantities of product were chosen. Details about the treatments are summarized in Table 1. The application by brush (Figure 1d) was used to simulate a typical procedure commonly employed in field conditions. Before the application of the product, the samples of stone were conditioned in equilibrium with the surrounding environment ( $24 \mathrm{~h}$ in the laboratory, at $23 \pm 2{ }^{\circ} \mathrm{C}$ and $45 \pm 5 \%$ R.H.). Only a $5 \times 5 \mathrm{~cm}^{2}$ side for each specimen was treated (namely, the side without the inscribed sample's number).

Table 1. Details of the treatments for the evaluation of the optimal amount of product.

\begin{tabular}{cccc}
\hline Samples & $\begin{array}{c}\text { Suggested Coverage } \\
\left(\mathbf{m}^{\mathbf{2}} / \mathbf{L}\right)\end{array}$ & $\begin{array}{c}\text { Actual Amount of Product } \\
(\mathbf{m L} / \text { specimen })\end{array}$ & $\begin{array}{c}\text { Consumption } \\
\left(\mathbf{L} / \mathbf{m}^{2}\right)\end{array}$ \\
\hline $\mathrm{PT}_{2}$ & 2 & 1.25 & 0.200 \\
$\mathrm{PT}_{3}$ & 3 & 0.83 & 0.248 \\
$\mathrm{PT}_{4}$ & 4 & 0.62 & 0.332 \\
$\mathrm{PT}_{5}$ & 5 & 0.50 & 0.500 \\
\hline
\end{tabular}

After the application of the product, all the specimens were kept in laboratory conditions, at $23 \pm 2{ }^{\circ} \mathrm{C}$ and $45 \pm 5 \%$ R.H., for 30 days. Then, they were dried in the oven at $40{ }^{\circ} \mathrm{C}$ until a constant weight was achieved, controlling the stabilization by periodical measurements of weight.

Color measurements and water absorption by the "contact sponge" test were performed to assess the harmlessness and the efficacy of the treatments, respectively. These methods were selected to evaluate the fundamental performance of the protective coating in a quick and simple manner, using standard tests easy to apply and reproduce in the field, which have been proposed also by other research groups for in situ analysis in historical buildings, for instance, monuments of Matera [34] and Catania [35]. Contact angle measurements were also carried out to control the surface hydrophobicity.

As it will be illustrated and discussed in Section 3.1, the treatment labeled with $\mathrm{PT}_{3}$ yielded a more suitable performance. Therefore, only the $\mathrm{PT}_{3}$ specimens (i.e., those related to the coverage of $3 \mathrm{~m}^{2} / \mathrm{L}$ ) were taken to complete the assessment of the protective capability of the treatment. In particular, a water vapor transmission test was performed to control the harmlessness of the treatment and its compatibility with the stone material; 
capillary water absorption was also monitored to evaluate the efficacy of the applied coating against water ingress.

\subsubsection{Anti-Graffiti Evaluation}

Staining was carried out with the acrylic blue-colored paint (Figure 1e), applied on both untreated and protected stone samples. The paint was sprayed in two coats on specimens placed on a $45^{\circ}$ tilted surface. The lateral sides of the specimens were protected with a PET film. The distance between the sample surface and the nebulizer was about $15 \mathrm{~cm}$. After the application of the paint, the samples were stored for 2 days in laboratory conditions $\left(23 \pm 2{ }^{\circ} \mathrm{C}, 50 \pm 5 \%\right.$ R.H. $)$.

The sprayed paint was removed, 15 days after its application, using the chemical remover described in Section 2.1. According to the recommendation reported in the technical data sheet, the remover was applied by brush (Figure 1f). After $25 \mathrm{~min}$ of action, a partial absorption into the stone structure of both the gel remover and the paint started taking place. Therefore, to avoid that the movement of the paint beneath the surface could reduce the cleaning efficacy, removal with a sponge was carried out $30 \mathrm{~min}$ after the application of the gel remover. Finally, the surfaces were rinsed using running tap water and a sponge (Figure 1f). The samples, dried for $24 \mathrm{~h}$ in laboratory conditions (i.e., $23 \pm 2{ }^{\circ} \mathrm{C}$ and $50 \pm 5 \%$ R.H.), were subjected to color measurements to quantify the cleaning efficacy. Due to initial unsatisfactory results, the removal was repeated using the same procedure and the final cleaning efficacy was calculated.

\subsubsection{Outdoor Exposure}

To assess the durability of the coating against natural weathering, untreated and protected stone samples were outdoor exposed. Color measurements, water absorption by the "contact sponge" test and contact angle measurements were performed just before the exposure. The specimens were, then, placed at $45^{\circ}$ on a holder (Figure 1g), with the surfaces exposed to the south, on the roof of the Department of Innovation Engineering building, on the Ecotekne Campus of Salento University, Lecce (latitude $=40^{\circ} 20^{\prime} 02.5^{\prime \prime} \mathrm{N}$, longitude $=18^{\circ} 06^{\prime} 50.0^{\prime \prime} \mathrm{E}$ ). The exposure started in mid-May. Some of the specimens were removed after 4 weeks of exposure, and the experimental investigations were repeated on these samples.

The meteoclimatic data measured during the period of exposure by a weather station close to the site of exposure are reported in Table 2.

Table 2. Meteoclimatic data during the period of outdoor exposure.

\begin{tabular}{ccccc}
\hline & Daily Average & Maximum & Minimum & Cumulative \\
\hline $\mathrm{T}\left({ }^{\circ} \mathrm{C}\right)$ & 22.2 & 34.1 & 12.4 & - \\
$\mathrm{R} . \mathrm{H} .(\%)$ & 67.2 & 99.7 & 26.3 & - \\
Rain $(\mathrm{mm})$ & - & 0.8 & 0.0 & 5.2 \\
Solar light dose $\left(\mathrm{MJ} / \mathrm{m}^{2}\right)$ & 0.04 & 0.08 & 0.00 & 30.02 \\
Wind speed $(\mathrm{m} / \mathrm{s})$ & 2.031 & 6.971 & 0.017 & - \\
\hline
\end{tabular}

\subsection{Experimental Investigations}

Color measurements [36] were performed with a Konica Minolta spectrophotometer CM-700d; CIE Standard illuminant D65 and the target mask $8 \mathrm{~mm}$ in diameter were used. Ten measurements were performed on each specimen and the instrument was recalibrated to a white calibration cap before each measurement session. The color coordinates were expressed in the CIE L* $a^{*} b^{*}(1976)$ color space: $L^{*}$, ranging from 0 (representing black) to 100 (white), indicates the lightness/darkness; $\mathrm{a}^{*}$ correspond to the red (positive values) green (negative values) coordinate; $b^{*}$ is the yellow /blue coordinate (with positive values related to yellow and negative to blue). 
The total color changes $\left(\Delta \mathrm{E}_{\mathrm{ab}}^{*}\right)$ were determined by the formula:

$$
\Delta \mathrm{E}_{\mathrm{ab}}^{*}=\left[\left(\Delta \mathrm{L}^{*}\right)^{2}+\left(\Delta \mathrm{a}^{*}\right)^{2}+\left(\Delta \mathrm{b}^{*}\right)^{2}\right]^{1 / 2},
$$

where: $\Delta \mathrm{L}^{*}, \Delta \mathrm{a}^{*}$, and $\Delta \mathrm{b}^{*}$ are the variation in each color parameter.

The color variations, after the coating application and in the evaluation of the antigraffiti efficacy, were calculated in comparison to the untreated surface; the color changes after the outdoor exposure were evaluated using the color parameters measured just before and after the exposure.

The water absorption was investigated by a standardized procedure [37] feasible in the field, that is, the "contact sponge" test [38]. A Petri dish, $3.5 \mathrm{~cm}$ in diameter, containing a moist disc-shaped sponge (area of $9.29 \mathrm{~cm}^{2}$ ), was used. All the tests were performed on stone samples dried in an oven for $24 \mathrm{~h}$ at $40{ }^{\circ} \mathrm{C}$, then, stored for $24 \mathrm{~h}$ in laboratory conditions (at $23 \pm 2{ }^{\circ} \mathrm{C}$ and $45 \pm 5 \%$ R.H.). First, $1 \mathrm{~mL}$ of water was added to the moist sponge inside the Petri dish and the "contact sponge" system (i.e., Petri dish, sponge and added water) was weighted. The lid was removed and the sponge inside the dish was pressed against the specimen placed almost vertically (tilted at $45^{\circ}$ ), to simulate a small part of a wall. To assure that the whole surface of the sponge touched the stone, a sponge, approximately $1 \mathrm{~mm}$ thicker than the Petri dish, was used; furthermore, the pressure suitable to provide complete contact between the dish's borders and the surface was applied. The time of contact between the wet sponge and the surfaces under investigation was fixed at $1 \mathrm{~min}$. The lid was promptly replaced to avoid water evaporation and the "contact sponge" system was weighed again. The water absorption was, then, calculated as follows:

$$
\mathrm{WA}=\left(\mathrm{m}_{\mathrm{i}}-\mathrm{m}_{\mathrm{f}}\right) /(\mathrm{A} \times \mathrm{t}),
$$

where: $m_{i}$ is the initial weight of the "contact sponge" system; $m_{f}$ is the weight of the "contact sponge" system after the contact with the stone surface; A is the area of the sponge; $t$ is the contact time. At the end of the test, the sponge was squeezed to remove the residual water, each specimen was dried in an oven at $40^{\circ} \mathrm{C}$ for $24 \mathrm{~h}$.

Following the procedure described in the European standard [39], water-stone static contact angle measurements were carried out. A Costech apparatus (Costech International S.p.A., Cernusco sul Naviglio, Milan, Italy) was used to deposit micro-drops of deionized water on the stone surfaces, while a connected camera recorded the image of the drop; the related contact angle was calculated by means of the "anglometer 2.0" software (Costech). Thirty measurements for each specimen were performed on different positions of the surface, averaging the obtained results. The image of each drop was acquired $15 \mathrm{~s}$ after deposition to assure the reproducibility of the test. It is to point out that the contact angle was not determinable for the untreated "Lecce stone": due to the high porosity of such stone material, in fact, water absorption was very high and rapid, hence the drops of water were suddenly absorbed.

The water vapor transport properties of the stone were assessed by the vapor transmission test. The parameters were evaluated at $20^{\circ} \mathrm{C}$, placing the containers with the samples into desiccators with silica gel and storing them in a climatic chamber (ACS Angelantoni Climatic Systems, Mod.UY 600, Massa Martana, Perugia, Italy). Every 24 h, weight measurements were carried out to calculate the rate of vapor transport through the sample from water in the container (where the R.H. was very close to 100\%) to the regulated atmosphere into the desiccator (R.H. 15\%, $1 \mathrm{~atm}$ ). Further details of the procedure are reported in a previous paper [40]. The cumulative mass decrease recorded during the test was plotted versus time and the water vapor flow rate $(G)$ was calculated as the slope of the curve. The water vapor transmission rate (WVTR), referred to as permeability in [41], being the mass of water vapor passing through the surface unit in the unit time $(24 \mathrm{~h})$, was calculated by the equation:

$$
\operatorname{WVTR}=\Delta \mathrm{M} /(\mathrm{t} \times \mathrm{A}),
$$


where: $\Delta \mathrm{M}$, expressed in $\mathrm{g}$, is the weight change in the steady state water vapor diffusion flow through the specimen (achieved when the difference between two subsequent measurements is lower than 5\% [41]); $\mathrm{A}$ is the area (in $\mathrm{m}^{2}$ ) exposed to water vapor; $\mathrm{t}$ is the unit time $(24 \mathrm{~h})$. In this study, $\Delta \mathrm{M}$ was calculated as the average of five consequent values of the daily difference in weight; the exposed area was $0.001611 \mathrm{~m}^{2}$.

The reduction of the vapor permeability (RVP) was also quantified after the application of the protective coating, using the following formula [42]:

$$
\mathrm{RVP} \%=\left[\left(\Delta \mathrm{M}_{\mathrm{u}}-\Delta \mathrm{M}_{\mathrm{x}}\right) / \Delta \mathrm{M}_{\mathrm{u}}\right] \times 100,
$$

where: $\Delta \mathrm{M}_{\mathrm{u}}$ and $\Delta \mathrm{M}_{\mathrm{x}}$ are the weight changes in the steady state for the untreated and the treated samples, respectively.

The capillarity water absorption test was performed according to the European standard [43]. The test was carried out for 6 days. At each time of exposure, the amount of absorbed water $(\mathrm{Qi})$ was calculated as follows:

$$
\mathrm{Q}_{\mathrm{i}}=\left(\mathrm{w}_{\mathrm{i}}-\mathrm{w}_{0}\right) / \mathrm{A}
$$

where: $w_{i}$ and $w_{0}$ are the weight of the sample at time $t_{i}$ and $t_{0}$, respectively; $A$ is the area exposed to water. $Q_{i}$ values were plotted versus the square root of time to evaluate the trend of water absorption.

All the weight measurements were acquired by an analytical balance (Sartorius AG, Model BP 2215, Göttingen, Germany) with an accuracy of $\pm 0.1 \mathrm{mg}$.

During the preparation of samples, the application of products and the performance of tests, the environmental conditions were continuously monitored by a thermo-hygrometer (Mod. EMR812HGN, Oregon Scientific Inc., Tualatin, OR, USA) able to collect temperature from $-50{ }^{\circ} \mathrm{C}$ to $70{ }^{\circ} \mathrm{C}$ (with a resolution of $0.1^{\circ} \mathrm{C}$ ) and relative humidity in the range 2-98\% (with a resolution of $\pm 1 \%$ ).

After the removal of the spray paint, the cleaning efficacy (CE) was evaluated as a percentage by the following Equation [18]:

$$
\mathrm{CE}=\left\{1-\left[\left(\Delta \mathrm{E}_{\mathrm{ab}}^{*}\right)_{\text {cleaned }} /\left(\Delta \mathrm{E}_{\mathrm{ab}}^{*}\right)_{\text {stained }}\right]\right\} \times 100 \text {, }
$$

where: $\left(\Delta \mathrm{E}^{*}{ }_{\mathrm{ab}}\right)_{\text {cleaned }}$ is the color variation of the cleaned surfaces; $\left(\Delta \mathrm{E}^{*}{ }_{\mathrm{ab}}\right)_{\text {stained }}$ is the color variation of the stained surfaces.

\section{Results and Discussion}

\subsection{Evaluation of the Optimal Amount of Product}

Color parameters, water absorption measured by the "contact sponge" test, and waterstone static contact angle values, determined on the stone samples before and after the treatments performed with the eco-friendly protective product, as described in Section 2.2.1, are reported in Table 3.

After the application of the coating in different quantities, very slight and comparable variations in the color parameters were measured, regardless of the amount of treatment. The following trend was observed: not significant decreases in $\mathrm{L}^{*}$; small increases in $\mathrm{a}^{*}$ and $b^{*}$ (Table 3). As illustrated in Figure 2, a very low value was measured for $\Delta \mathrm{E}^{*}{ }_{\mathrm{ab}}$ for all the samples, it did never exceed the value perceivable by the naked eye, that is, $\Delta \mathrm{E}_{\mathrm{ab}}^{*}=3[44,45]$. The observed colored variations are lower than those obtained after the application of other commercial protective products on Lecce stone. $\Delta \mathrm{E}_{\mathrm{ab}}^{*}$ around 4 units was measured applying fluorine-based polymers [17]; using siloxanes as coatings, $\Delta \mathrm{E}_{\mathrm{ab}}^{*}$ higher than 2 units were found [46], while lower values were obtained only using lower but ineffective amounts of product [40]. The different amounts of protective product applied on Lecce stone caused similar negligible color changes to the stone surfaces: the lowest $\Delta \mathrm{E}^{*}$ ab value was measured, in fact, for $\mathrm{PT}_{2}$ samples (i.e., the surfaces treated with the highest quantity of product). 
Table 3. Color parameters $\left(\mathrm{L}^{*}, \mathrm{a}^{*}, \mathrm{~b}^{*}\right)$, color change $\left(\Delta \mathrm{E}^{*} \mathrm{ab}\right)$, water absorption by "contact sponge" test (WA), and water-stone static contact angle $(\alpha)$ in the samples before and after the application of the protective treatments.

\begin{tabular}{cccc}
\hline & Samples & Before Protection & After Protection \\
\hline & $\mathrm{PT}_{2}$ & $82.54 \pm 0.50$ & $82.04 \pm 0.44$ \\
$\mathrm{~L}^{*}$ & $\mathrm{PT}_{3}$ & $82.64 \pm 0.53$ & $81.64 \pm 0.44$ \\
& $\mathrm{PT}_{4}$ & $82.52 \pm 0.60$ & $81.81 \pm 0.24$ \\
& $\mathrm{PT}_{5}$ & $83.04 \pm 0.36$ & $82.25 \pm 0.58$ \\
\hline & $\mathrm{PT}_{2}$ & $2.02 \pm 0.18$ & $2.10 \pm 0.14$ \\
$\mathrm{PT}_{3}$ & $1.94 \pm 0.13$ & $2.15 \pm 0.10$ \\
& $\mathrm{PT}_{4}$ & $2.00 \pm 0.13$ & $2.13 \pm 0.09$ \\
& $\mathrm{PT}_{5}$ & $2.12 \pm 0.15$ & $2.26 \pm 0.14$ \\
\hline & $\mathrm{PT}_{2}$ & $14.05 \pm 0.46$ & $15.08 \pm 0.42$ \\
$\mathrm{~b}^{*}$ & $\mathrm{PT}_{3}$ & $13.91 \pm 0.51$ & $15.38 \pm 0.41$ \\
& $\mathrm{PT}_{4}$ & $13.80 \pm 0.45$ & $14.79 \pm 0.42$ \\
& $\mathrm{PT}_{5}$ & $14.73 \pm 0.44$ & $15.62 \pm 0.50$ \\
\hline & $\mathrm{PT}_{2}$ & $99.95 \pm 5.24$ & $3.83 \pm 1.70$ \\
$\mathrm{PT}_{3}$ & $87.00 \pm 3.68$ & $0.66 \pm 0.10$ \\
$\left(\mathrm{mg} / \mathrm{min} \times \mathrm{cm}^{2}\right)$ & $\mathrm{PT}_{4}$ & $83.24 \pm 4.03$ & $0.65 \pm 0.08$ \\
& $\mathrm{PT}_{5}$ & $87.60 \pm 4.23$ & $0.62 \pm 0.11$ \\
\hline & $\mathrm{PT}_{2}$ & Not determinable & $141 \pm 6$ \\
& $\mathrm{PT}_{3}$ & Not determinable & $141 \pm 4$ \\
$\mathrm{PT}_{4}$ & Not determinable & $132 \pm 4$ \\
$\left.{ }^{\circ}\right)$ & $\mathrm{PT}_{5}$ & Not determinable & $140 \pm 4$ \\
\hline
\end{tabular}

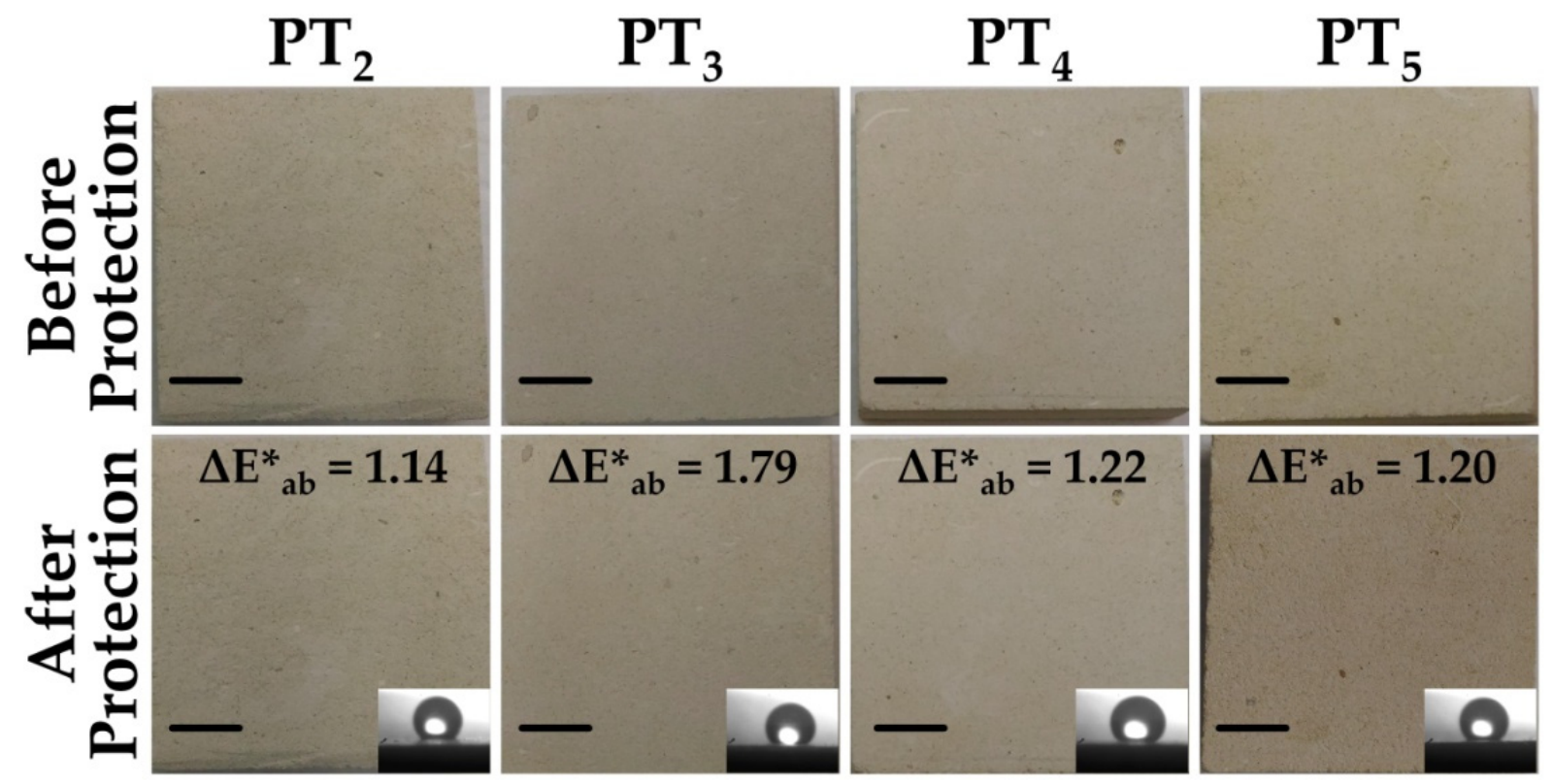

Figure 2. Stone specimens before and after the application of the protective treatments; the color changes (as $\Delta \mathrm{E}^{*}$ ab) and water droplets on the protected stone surfaces are shown. Each scale bar indicates $1 \mathrm{~cm}$.

The water absorption, measured by the "contact sponge" test, strongly declined after the treatments; reductions above $96 \%$ was calculated in all the samples, in accordance with the results obtained during a monitoring campaign carried out on the façades of monuments, made with Lecce stone, treated with siloxane polymers [47].

It is to highlight, however, that, as reported in Table 3 and illustrated in Figure 3 the highest amount of product $\left(\mathrm{PT}_{2}\right.$ specimens) did not assure the highest reduction in water absorption: decreases of $99 \%$ were measured for the samples $\mathrm{PT}_{3}, \mathrm{PT}_{4}$, and $\mathrm{PT}_{5}$, 
while a reduction of $96 \%$ was found for $\mathrm{PT}_{2}$. Similar behavior was observed in a previous study [40] when a larger quantity of applied protective product caused a poor barrier against water ingress due to the presence of fractured coatings. Cracks in coatings can be, in fact, generated during the drying/hardening [48] as a consequence of shrinkage promoted by the evaporation of water, solvents or reactions' by-products, and they are frequently observed in siloxane-based coatings [49]. Anyway, in any kind of coating, the presence of fractures is strongly dependent on the coating's thickness [50], with a critical value above which the cracks start to occur [51].

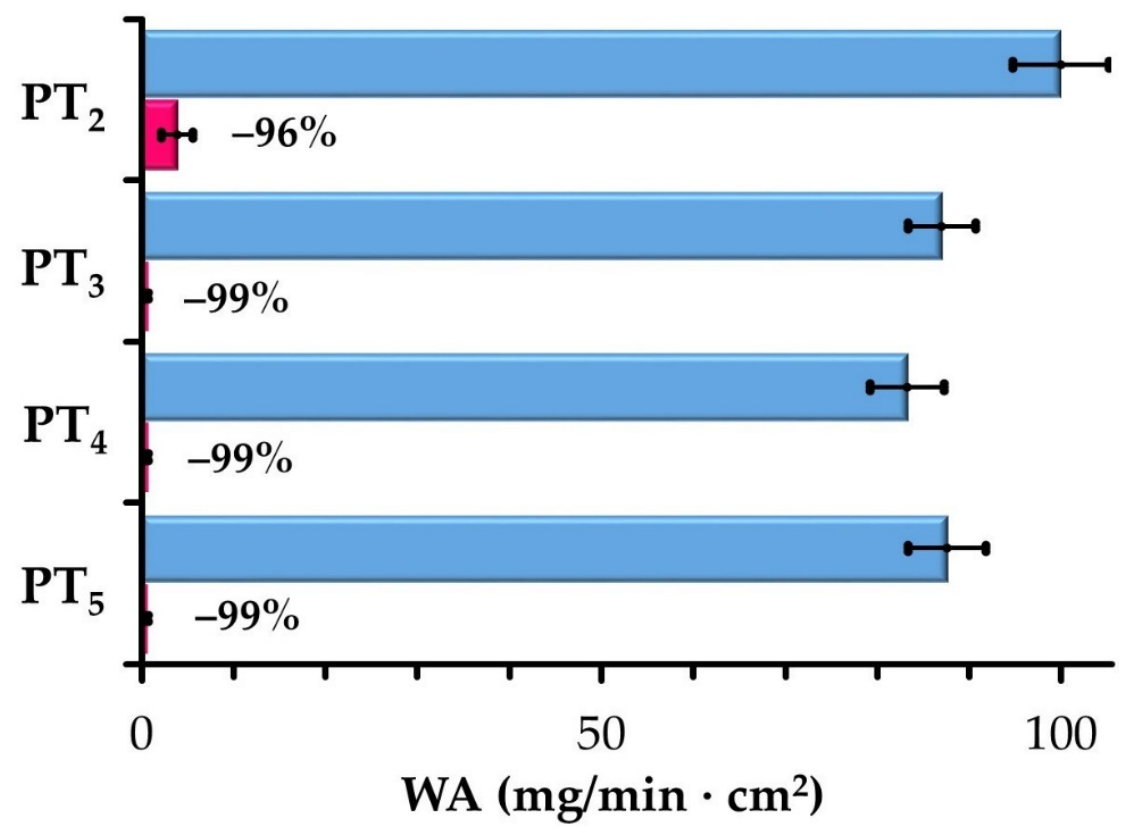

\section{$\exists$ Before Protection $\square$ After Protection}

Figure 3. Water absorption by "contact sponge" test (WA) before and after the application of the protective treatments; the variation in percentage is also reported.

In the $\mathrm{PT}_{2}$ samples, due to the greater amount of applied product, the presence of a thicker coating can be inferred: thus, an excessive accumulation of the polymer on the stone surface cannot be excluded. This condition might be the cause of coatings affected by microcracks which reduce their ability to act as a barrier against water ingress into the stone. Further investigations are in progress to confirm this hypothesis.

As explained in Section 2.3, water-stone contact angle cannot be determined on untreated stone surfaces, while contact angles greater than $130^{\circ}$ were measured on all the protected samples, as reported in Table 3 . No clear dependence on the quantity of applied product was observed, the lowest value was measured on the $\mathrm{PT}_{4}$ sample.

On the basis of these results, the evaluation of color changes did not allow discriminating the proper amount of product. Trying to find a balance between strong reduction in water absorption and high surface hydrophobicity, the quantity corresponding to the coverage of $3 \mathrm{~m}^{2}$ per liter of product (i.e., $\mathrm{PT}_{3}$ treatment) was selected to complete the evaluation of the protective treatment.

\subsection{Harmlessness of the Treatment}

Color variations as a consequence of conservative treatments on stone surfaces certainly have a great impact since they can be appreciated also by the naked eye. Changes in water vapor transport properties are other important parameters to take into consideration in evaluating the harmlessness of the treatment itself. This is because, if the permeability to water vapor is strongly reduced after the application of a coating, water may condensate at 
the interface between the treated and untreated stone regions, thus producing mechanical stress able to activate processes of decay [52].

With this perspective, the water vapor transport properties were evaluated on the same specimens before and after applying the $\mathrm{PT}_{3}$ treatment. The mass changes measured during these tests are reported in Figure 4: linear trends were always found, with the steady state of water vapor diffusion flow through the specimen observed from $72 \mathrm{~h}$ after the beginning of the test up until its end. Slight reductions were measured for the water vapor transport parameters (reported in Table 4) which are, however, comparable to those obtained for neat "Lecce stone" [40] and for the same material protected with commercial coatings; in other studies, WVTR was found approximately $180 \mathrm{~g} / \mathrm{m}^{2} \times 24 \mathrm{~h}$ after the application of fluorine-based products [17], while ranging between 166 and $188 \mathrm{~g} / \mathrm{m}^{2} \times 24 \mathrm{~h}$, depending on the applied amount of product, using siloxane-based protective coatings [40].

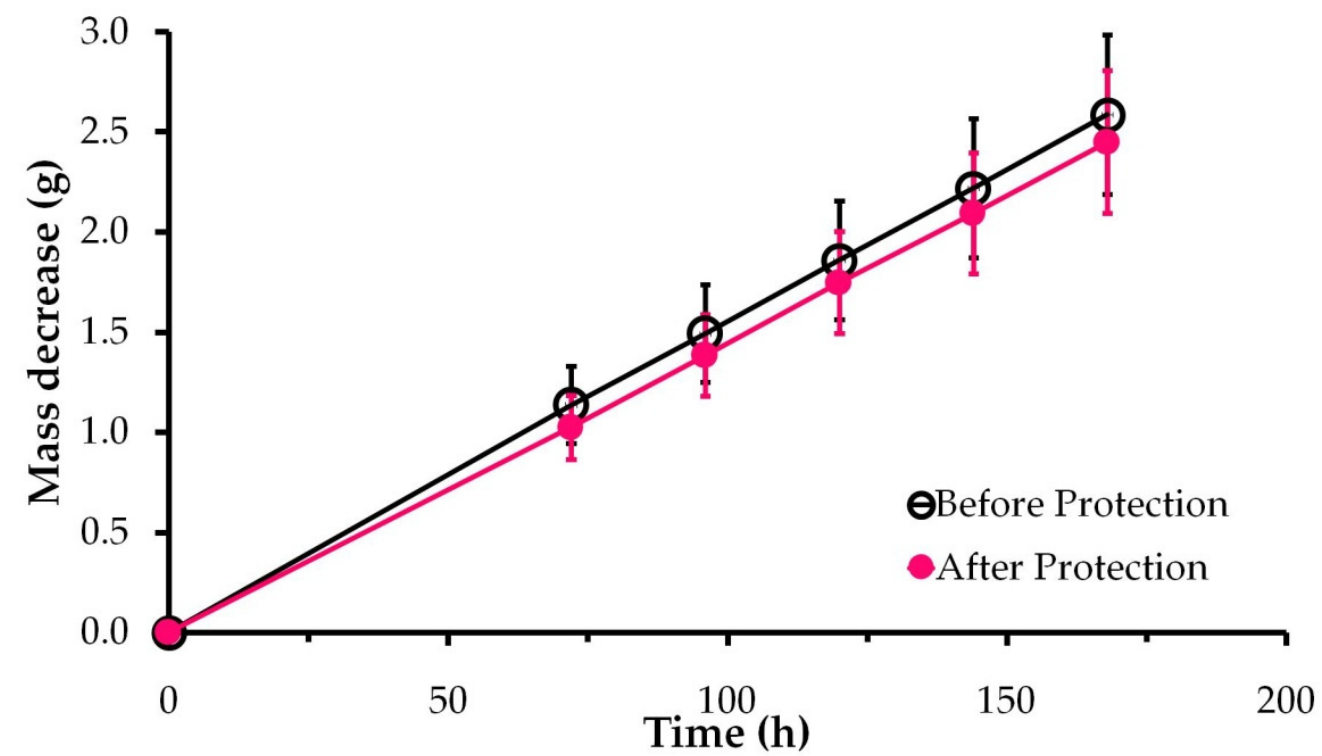

Figure 4. Mass decrease, as a function of time, measured during the water vapor permeability test.

Table 4. Water vapor flow rate (G) and water vapor transmission rate (WVTR) in the untreated and protected stone samples; the reduction of the vapor permeability (RVP) after the protective treatment is also reported.

\begin{tabular}{ccc}
\hline & Untreated & Protected \\
\hline $\mathrm{G}\left((\mathrm{g} / \mathrm{h}) \times 10^{-3}\right)$ & $15.4 \pm 2.4$ & $14.6 \pm 2.1$ \\
$\mathrm{WVTR}\left(\mathrm{g} / \mathrm{m}^{2} \times 24 \mathrm{~h}\right)$ & $212 \pm 30$ & $196 \pm 26$ \\
$\mathrm{RVP}(\%)$ & - & $8 \pm 4$ \\
\hline
\end{tabular}

The permeability decrease (reported as RVP in Table 4) was to be very low, with the measured reduction well below the threshold of $20 \%$ accepted as tolerable for treated stone materials in buildings and monuments [53]. These results gave evidence of the harmlessness and compatibility of the applied treatment with respect to the "Lecce stone".

\subsection{Protective Efficacy}

\subsubsection{Barrier against Water Ingress}

Capillary water absorption curves, determined on the stone samples before and after the $\mathrm{PT}_{3}$ treatment, are compared in Figure 5. 


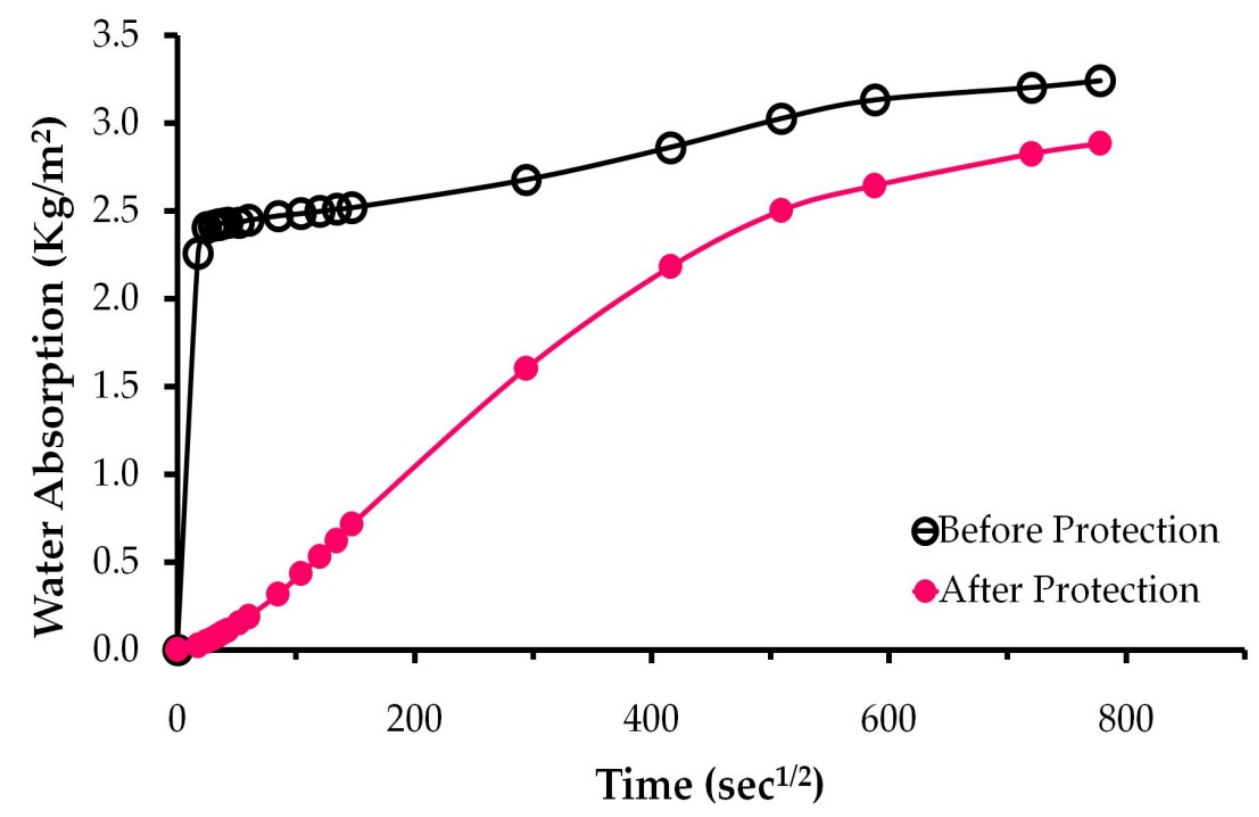

Figure 5. Curves of water absorption by capillarity before and after the $\mathrm{PT}_{3}$ treatment.

Referring to the specimens without the protective coating, most of the water absorption (i.e., 75\%) occurred within the first $10 \mathrm{~min}$ of exposure; at the end of the test (after 7 days of exposure), the total amount of absorbed water was $3.24 \mathrm{~kg} / \mathrm{m}^{2}$; this result is comparable to that reported in the literature for this uncoated stone, that is, water absorption very low at the beginning of the water exposure [54], achieving values of approximately $4 \mathrm{~kg} / \mathrm{m}^{2}$ [55] or above [56]. After the application of the treatment, the water absorption was strongly limited, especially in the early steps of the test. Over the whole experiment performed on the protected specimens, the absorption values were substantially lower than those measured on the uncoated samples of Lecce stone. Only 55\% of the absorbed water was gained after $24 \mathrm{~h}$ of exposure; at longer times, the differences among treated and untreated specimens were reduced, with the total quantity of water absorbed by capillarity at the end of the test of $2.88 \mathrm{~kg} / \mathrm{m}^{2}$, that is, $-11 \%$ in comparison to the result found for the samples without protection. In other studies, at the end of the test (i.e., 8 days), where commercial siloxane-based polymers were applied on Lecce stone the capillary water absorption still remained very low (about $-90 \%$ in comparison to the untreated stone [46]), while using commercial fluorinated coatings the protective action against water ingress was almost completely lost after the first $24 \mathrm{~h}$ [18].

The observed behavior is in agreement with the strong reduction in water absorption measured by the "contact sponge" test. Although this latter experiment evaluates only the short-term water uptake, it has similar sensitivity if compared to the capillary rise method [57] and other well-established tests for evaluation of water absorption [38]. Therefore, such a result confirms that significant information about the water absorption behavior can be obtained by a simple and cheap "contact sponge" test, easily feasible also in the field [47].

\subsubsection{Anti-Graffiti Action}

In addition to the good protective performance illustrated in the previous sections, the applied product acted also as a good anti-graffiti since the cleaning of the stone surfaces stained by spray paint was more effective in the area where the protective coating was applied.

A first cleaning step allowed achieving a CE value of $80 \%$ for the treated samples, while CE below $50 \%$ was obtained on the stained neat stone subjected to the same procedure of paint removal. In fact, $\mathrm{CE}=80 \%$ is the lower threshold to judge as adequate for the removal of the staining agent [18]. These results were also evident to the visual inspection 
by the naked eye: as observable in Figure 6, the paint was partially removed and only in limited areas of the untreated stone surfaces; on the other hand, most of the protected stone surface appeared without the blue paint, even if some parts were still affected by the staining agent.

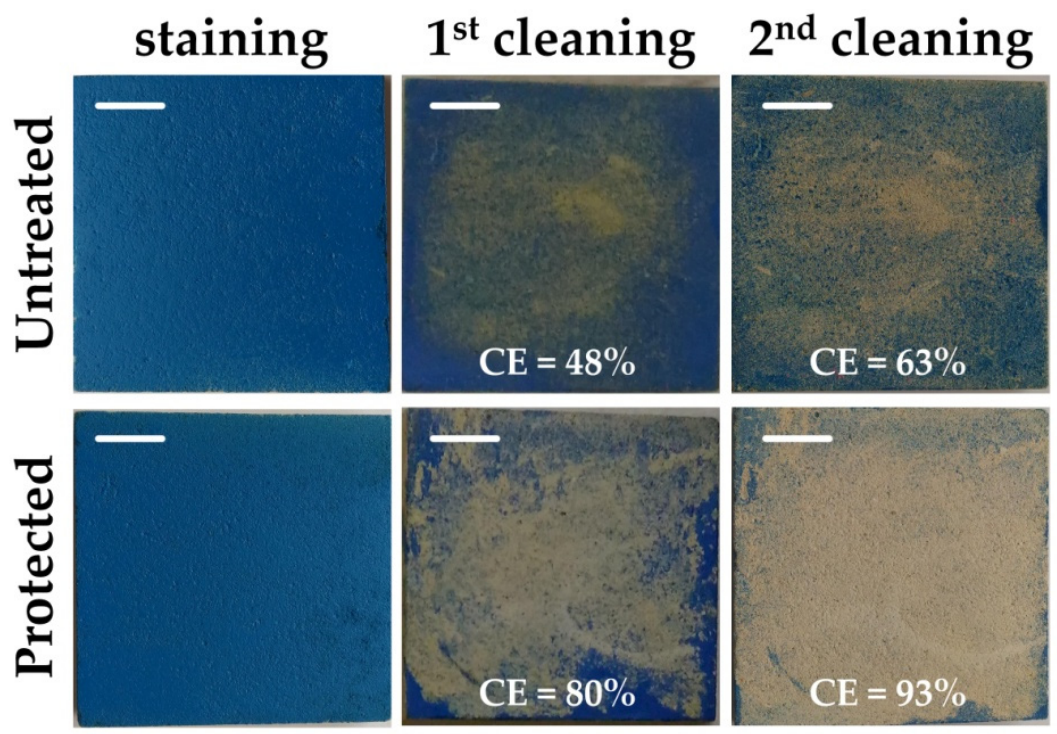

Figure 6. Untreated and protected stone samples after the staining and after the cleaning actions; the $\mathrm{CE}$ values, as defined in Equation (6), are reported. Each scale bar indicates $1 \mathrm{~cm}$.

A second removal step was performed in order to try to improve the cleaning. Actually, the second cleaning resulted in more effectiveness on both coated and uncoated specimens. However, the paint was well visible on the untreated stone surfaces, with a $\mathrm{CE}$ value that increased to $63 \%$, i.e., a value still not acceptable; CE above $90 \%$ was calculated for the protected samples, confirming an effective stain removal, as also clearly evident to the visual observation (Figure 6). It is to point out that for Lecce stone surfaces, protected with other commercial anti-graffiti systems (either siloxane or fluorine-based) and stained with blue acrylic spray paint, the CE values did not exceed 75\% [18].

As described in Section 2.2.2, the time of remover's application was restricted to $30 \mathrm{~min}$ because, during the first cleaning (after $25 \mathrm{~min}$ ), a partial absorption into the stone of both remover and paint was observed. Using the double procedure, the penetration of the paint inside the stone was avoided or strongly restricted, at least. Therefore, the cleaning performed in two shorter steps, rather than only one remover's application twice longer, was successful and probably more effective. On the other hand, the penetration of the staining agent into the pores of the substrate can compromise the cleaning efficacy, especially in a porous stone material, such as Lecce stone [23].

\subsection{Durability to Short-Term Natural Aging}

The changes in the color parameters as a consequence of the 1-month outdoor exposure resulted very low, as reported in Table 5. Small increases in $\mathrm{L}^{*}$ and decreases in $\mathrm{a}^{*}$ and $\mathrm{b}^{*}$ were, in fact, measured. Similar variations were found irrespective of the performed treatment: only the change in $\mathrm{b}^{*}$ was higher for the protected samples with respect to the untreated ones. A lower $\mathrm{b}^{*}$ parameter contributed to obtaining $\Delta \mathrm{E}^{*} \mathrm{ab}$ more pronounced in the protected samples, achieving values above 3 units. As already reported in Section 3.1, although the latter result can mean color changes perceivable by the naked eye, it is to take into account that in the field of restoration of heritage buildings, a total color difference smaller than 5 units is judged acceptable in evaluating the effects of stone treatments [58] as well as the stability over time of the conservative coating [59]. Since the variations in the color parameters were comparable in both the sets of samples (protected and neat stones), the color changes were probably due to the deposition of airborne particles on the surfaces, 
a phenomenon occurring also in the unprotected samples, rather than to the presence of the coating or to the polymer's degradation, taking also into account the shorter period of exposure (i.e., 1 month). On the other hand, color variations in stone samples treated with a fluorinated polymer were already connected to the presence on the surface of particles from the outdoor environment [60].

Table 5. Color parameters $\left(\mathrm{L}^{*}, \mathrm{a}^{*}, \mathrm{~b}^{*}\right)$, color change $\left(\Delta \mathrm{E}^{*} \mathrm{ab}\right)$, water absorption by "contact sponge" test (WA), and water-stone static contact angle $(\alpha)$ in the samples before and after the application of the protective treatments.

\begin{tabular}{ccccc}
\hline & Samples & Before Exposure & After Exposure & Variation \\
\hline \multirow{2}{*}{$\mathrm{L}^{*}$} & Untreated & $82.27 \pm 0.36$ & $84.72 \pm 0.42$ & $2.45 \pm 0.12$ \\
& Protected & $82.12 \pm 0.82$ & $84.95 \pm 0.74$ & $2.83 \pm 0.34$ \\
\hline \multirow{2}{*}{$\mathrm{a}^{*}$} & Untreated & $2.17 \pm 0.08$ & $1.55 \pm 0.13$ & $-0.62 \pm 0.01$ \\
& Protected & $2.10 \pm 0.26$ & $1.43 \pm 0.28$ & $-0.67 \pm 0.07$ \\
\hline \multirow{2}{*}{$\mathrm{b}^{*}$} & Untreated & $15.36 \pm 0.62$ & $13.77 \pm 0.74$ & $-1.58 \pm 0.07$ \\
& Protected & $15.08 \pm 0.82$ & $12.52 \pm 0.92$ & $-2.56 \pm 0.28$ \\
\hline \multirow{2}{*}{$\Delta \mathrm{E}^{*} \mathrm{ab}$} & Untreated & - & $2.98 \pm 0.07$ & - \\
& Protected & - & $3.88 \pm 0.41$ & - \\
\hline $\mathrm{WA}$ & Untreated & $102.76 \pm 9.28$ & $100.36 \pm 7.36$ & $-2.40 \pm 1.92$ \\
$\left(\mathrm{mg} / \mathrm{min} \times \mathrm{cm}^{2}\right)$ & Protected & $0.82 \pm 0.15$ & $1.01 \pm 0.25$ & $0.19 \pm 0.13$ \\
\hline $\mathrm{A}$ & Untreated & N.D. & N.D. & - \\
$\left({ }^{\circ}\right)$ & Protected & $144 \pm 2$ & $134 \pm 5$ & $-10 \pm 3$ \\
\hline
\end{tabular}

N.D. $=$ Not determinable

The water absorption, measured by the "contact sponge" test, remained unchanged after 4 weeks of outdoor exposure (Table 5): the coating, therefore, was still able to act as a barrier against water ingress into the stone; the observed small differences were in the range of the experimental error.

Finally, a slight decrease in water-stone contact angle was found after the short-term natural aging, as can be observed from data reported in Table 5 . The measured variation was comparable to those reported in other studies for fluorinated protective products on Lecce stone under simulated solar radiation [61], as well as on specimens of compact stone materials exposed outdoor [62].

These results suggest that the polymer coating was not degraded under these conditions of exposure, therefore, their initial properties and performances were retained at shorter exposure times. Further experiments are underway to evaluate the durability of the coating after longer exposure times.

\section{Conclusions}

An eco-friendly hydrophobic coating, based on a fluorine-based polymer dispersed in water, was analyzed as surface treatment able to protect a very porous stone, i.e., Lecce stone.

The first part of the investigation was devoted to the optimization of the amount of the product to apply on the surface of Lecce stone elements. The comparison of results of color measurements, water absorption through "contact sponge" tests and contact angle analyses, carried out on the Lecce stone specimens before and after the treatments performed with the protective product under investigation, allowed to identify the quantity of product producing the best balance of hydrophobicity properties and water absorption characteristics, i.e., $3 \mathrm{~m}^{2}$ per liter of product. This amount was, then, employed for the pursuance of the study. The different tested amounts of the product applied on Lecce stone, on the other hand, produced only negligible modifications of the stone color.

In accordance with the "contact sponge" tests, the water absorption through capillary rise tests confirmed that the ingress of water was greatly reduced when the green coating 
was applied on the stone surface in comparison with un-protected specimens. Furthermore, the selected amount of protective product proven to produce only slight reductions in the water vapor transport properties of the treated stone with respect to the untreated specimens, allowing the water eventually contained in the substrate to come out and not cause damage to the stone.

As an additional advantage of the green product under analysis, it was also able to behave as a good anti-graffiti treatment: the cleaning of the Lecce stone surfaces, previously marked by a paint, in fact, had better success if the protective coating was applied.

The short-term outdoor durability of the coating applied on the Lecce stone surface was assessed by repeating the same described tests on treated and untreated stone elements after a four-week exposure in Lecce, Italy. It was found that the initial properties and performances of the eco-friendly product remained substantially unchanged after a month of outdoor exposure. Further studies are in progress to assess the durability of the coating after longer exposure times.

The study allowed also confirmation that the "contact sponge" tests can be used as an effective monitoring method to evaluate the water absorption of conservation/protection treatments.

Finally, it is to point out that some questions still remain unclear and require additional investigations. In particular, further experiments are necessary to verify the presence of microcracks in the coatings which might be the reason for lower ability to prevent water absorption. In addition, the evaluation of the coating's durability also needs to be broadened; in this regard, tests performed after longer outdoor exposure times are in progress.

Author Contributions: Conceptualization, M.L. and M.F.; Formal Analysis, M.L., M.M. and M.F.; Investigation, M.M., M.A. and D.D.; Writing—Review and Editing, M.L. and M.F.; Supervision, M.F. All authors have read and agreed to the published version of the manuscript.

Funding: This research received no external funding.

Institutional Review Board Statement: Not applicable.

Informed Consent Statement: Not applicable.

Data Availability Statement: The data presented in this study are available on request from the corresponding author. The data are not publicly available as they form part of an ongoing study.

Acknowledgments: The work is the outcome of a scientific collaboration carried out with IBIX Company (Santa Maria in Fabriago, Ravenna, Italy), which supplied the protective product under investigation. Thank are due to Assorestauro Association, with Arch. Cristina Caiulo, for the scientific network with IBIX Company. Thanks are also due to C.I.R. Chimica Italiana Restauri (Arezzo, Italy), and the Head of R\&D Sector Federico Paggini, for providing the chemical remover.

Conflicts of Interest: The authors declare no conflict of interest.

\section{References}

1. Catarino, L.; Gil, F.P.S.C.; Quinta-Ferreira, M.; Marques, F. Characterization and rehabilitation of the "porta férrea" stone materials, university of coimbra, portugal. Environ. Earth Sci. 2018, 77, 416. [CrossRef]

2. Leplat, J.; Bousta, F.; François, A.; Guiavarc'h, M.; Mertz, J.-D.; Brissaud, D. The pink staircase of sully-sur-loire castle: Even bacteria like historic stonework. Int. Biodeterior. Biodegrad. 2019, 145, 104805. [CrossRef]

3. Calia, A.; Laurenzi Tabasso, M.; Maria Mecchi, A.; Quarta, G. The study of stone for conservation purposes: Lecce Stone (Southern Italy). Geol. Soc. Lond. Spec. Publ. 2014, 391, 139. [CrossRef]

4. Punturo, R.; Russo, L.G.; Giudice, A.L.; Mazzoleni, P.; Pezzino, A. building stone employed in the historical monuments of Eastern Sicily (Italy). An example: The ancient city centre of Catania. Environ. Geol. 2006, 50, 156-169. [CrossRef]

5. Cassar, J. The use of limestone in a historic context-The experience of malta. Geol. Soc. Lond. Spec. Publ. 2010, 331, 13. [CrossRef]

6. Artesani, A.; Di Turo, F.; Zucchelli, M.; Traviglia, A. Recent advances in protective coatings for cultural heritage-An overview. Coatings 2020, 10, 217. [CrossRef]

7. Baglioni, P.; Chelazzi, D. How science can contribute to the remedial conservation of cultural heritage. Chem. A Eur. J. 2021, 27, 10798-10806. [CrossRef]

8. Sbardella, F.; Pronti, L.; Santarelli, M.L.; Asua Gonzàlez, J.; Bracciale, M. Waterborne acrylate-based hybrid coatings with enhanced resistance properties on stone surfaces. Coatings 2018, 8, 283. [CrossRef] 
9. Sbardella, F.; Bracciale, M.P.; Santarelli, M.L.; Asua, J.M. Waterborne modified-silica/acrylates hybrid nanocomposites as surface protective coatings for stone monuments. Prog. Org. Coat. 2020, 149, 105897. [CrossRef]

10. Esposito Corcione, C.; Striani, R.; Frigione, M. Novel hydrophobic free-solvent UV-cured hybrid organic-inorganic methacrylicbased coatings for porous stones. Prog. Org. Coat. 2014, 77, 803-812. [CrossRef]

11. Esposito Corcione, C.; Striani, R.; Frigione, M. Organic-inorganic UV-cured methacrylic-based hybrids as protective coatings for different substrates. Prog. Org. Coat. 2014, 77, 1117-1125. [CrossRef]

12. Ocak, Y.; Sofuoglu, A.; Tihminlioglu, F.; Böke, H. Sustainable bio-nano composite coatings for the protection of marble surfaces. J. Cult. Herit. 2015, 16, 299-306. [CrossRef]

13. Zucchelli, M.; Mazzon, G.; Bertolacci, L.; Carzino, R.; Zendri, E.; Athanassiou, A. Stone sustainable protection and preservation using a zein-based hydrophobic coating. Prog. Org. Coat. 2021, 159, 106434. [CrossRef]

14. Geurts, J.; Bouman, J.; Overbeek, A. New waterborne acrylic binders for zero VOC paints. J. Coat. Technol. Res. 2008, 5, 57-63. [CrossRef]

15. Ho, J.; Mudraboyina, B.; Spence-Elder, C.; Resendes, R.; Cunningham, M.F.; Jessop, P.G. Water-Borne coatings that share the mechanism of action of oil-based coatings. Green Chem. 2018, 20, 1899-1905. [CrossRef]

16. Hunek, D.B.-; Fic, S.; Styczen, J. Roughness and surface free energy of silicate brick hydrophobised with emulsions of low VOC content. IOP Conf. Ser. Mater. Sci. Eng. 2019, 471, 032012. [CrossRef]

17. Lettieri, M.; Masieri, M.; Morelli, A.; Pipoli, M.; Frigione, M. Oleo/hydrophobic coatings containing nano-particles for the protection of stone materials having different porosity. Coatings 2018, 8, 429. [CrossRef]

18. Lettieri, M.; Masieri, M.; Frigione, M. Novel nano-filled coatings for the protection of built heritage stone surfaces. Nanomaterials 2021, 11, 301. [CrossRef]

19. Lettieri, M.; Masieri, M.; Pipoli, M.; Morelli, A.; Frigione, M. Anti-graffiti behavior of oleo/hydrophobic nano-filled coatings applied on natural stone materials. Coatings 2019, 9, 740. [CrossRef]

20. Lettieri, M.; Masieri, M.; Frigione, M. Durability to simulated bird guano of nano-filled oleo/hydrophobic coatings for the protection of stone materials. Prog. Org. Coat. 2020, 148, 105900. [CrossRef]

21. IBIX Biocare Website. Available online: https://www.ibixbiocare.it/images/documenti/schede-tecniche/scheda-tecnica-protectitr.pdf (accessed on 4 October 2021).

22. Torrisi, A. Evaluation of five fluorinated compounds as calcarenite protectives. J. Cult. Herit. 2008, 9, 135-145. [CrossRef]

23. Lettieri, M.; Masieri, M. Surface characterization and effectiveness evaluation of anti-graffiti coatings on highly porous stone materials. Appl. Surf. Sci. 2014, 288, 466-477. [CrossRef]

24. Camaiti, M.; Bortolotti, V.; Cao, Y.; Papacchini, A.; Salvini, A.; Brizi, L. High efficiency fluorinated oligo(ethylenesuccinamide) coating for stone. Coatings 2021, 11, 452. [CrossRef]

25. Gemelli, G.M.C.; Zarzuela, R.; Fernandez, F.; Mosquera, M.J. Compatibility, effectiveness and susceptibility to degradation of alkoxysilane-based consolidation treatments on a carbonate stone. J. Build. Eng. 2021, 42, 102840. [CrossRef]

26. Bianco, L. Geochemistry, mineralogy and textural properties of the lower globigerina limestone used in the built heritage. Minerals 2021, 11, 740. [CrossRef]

27. Beck, K.; Al-Mukhtar, M.; Rozenbaum, O.; Rautureau, M. Characterization, water transfer properties and deterioration in tuffeau: Building material in the Loire Valley-France. Build. Environ. 2003, 38, 1151-1162. [CrossRef]

28. Ševčík, R.; Viani, A.; Mancini, L.; Appavou, M.-S.; Machová, D. Investigation of nano-microstructural changes in maastricht limestone after treatment with nanolime suspension. Appl. Phys. A 2020, 126, 367. [CrossRef]

29. Sena da Fonseca, B.; Ferreira Pinto, A.P.; Rodrigues, A.; Piçarra, S.; Montemor, M.F. The role of properties on the decay susceptibility and conservation issues of soft limestones: Contribution of Ançã Stone (Portugal). J. Build. Eng. 2021, 44 , 102997. [CrossRef]

30. Bugani, S.; Camaiti, M.; Morselli, L.; Van de Casteele, E.; Koen, J. Investigation on porosity changes of lecce stone due to conservation treatments by means of X-Ray nano- and improved micro-computed tomography: Preliminary results. X-ray Spectrom. 2007, 36, 316-320. [CrossRef]

31. Föllmi, K.B.; Hofmann, H.; Chiaradia, M.; de Kaenel, E.; Frijia, G.; Parente, M. Miocene phosphate-rich sediments in Salento (Southern Italy). Sediment. Geol. 2015, 327, 55-71. [CrossRef]

32. Tiano, P.; Accolla, P.; Tomaselli, L. Phototrophic biodeteriogens on lithoid surfaces: An ecological study. Microb. Ecol. 1995, 29, 299-309. [CrossRef] [PubMed]

33. UNI 10921: Beni Culturali Materiali Lapidei Naturali Ed Artificiali_Prodotti Idrorepellenti-Applicazione Su Provini E Determinazione in Laboratorio Delle Loro Caratteristiche; Ente Italiano di normazione: Milan, Italy, 2001.

34. Sacchi, B.; Vettori, S.; Andreotti, A.; Rampazzi, L.; Colombini, M.P.; Tiano, P. Assessment of water repellent treatments for the stone of the matera Cathedral Facade (Italy). Int. J. Archit. Herit. 2020, 1-9. [CrossRef]

35. Occhipinti, R.; Stroscio, A.; Maria Belfiore, C.; Barone, G.; Mazzoleni, P. Chemical and colorimetric analysis for the characterization of degradation forms and surface colour modification of building stone materials. Constr. Build. Mater. 2021, $302,124356$. [CrossRef]

36. EN 15886. Conservation of Cultural Property—Test Methods-Colour Measurement of Surfaces; CEN (European Committee for Standardization): Brussels, Belgium, 2010. 
37. UNI 11432: Beni culturali Materiali Lapidei Naturali Ed Artificiali-Misura Della Capacità Di Assorbimento Di Acqua Mediante Spugna Di Contatto; Ente Italiano di normazione: Milan, Italy, 2011.

38. Vandevoorde, D.; Pamplona, M.; Schalm, O.; Vanhellemont, Y.; Cnudde, V.; Verhaeven, E. Contact sponge method: Performance of a promising tool for measuring the initial water absorption. J. Cult. Herit. 2009, 10, 41-47. [CrossRef]

39. EN 15802. Conservation of Cultural Property-Test Methods-Determination of Static Contact Angle; CEN (European Committee for Standardization): Brussels, Belgium, 2010.

40. Lettieri, M.; Masieri, M. Performances and coating morphology of a siloxane-based hydrophobic product applied in different concentrations on a highly porous stone. Coatings 2016, 6, 60. [CrossRef]

41. NORMAL Rec. 21/85 Permeabilità al Vapor D'acqua; CNR/ICR: Rome, Italy, 1985.

42. Karapanagiotis, I.; Hosseini, M. Superhydrophobic coatings for the protection of natural stone. In Advanced Materials for the Conservation of Stone; Hosseini, M., Karapanagiotis, I., Eds.; Springer International Publishing: Cham, Switzerland, 2018; pp. 1-25. ISBN 978-3-319-72260-3.

43. EN 15801. Conservation of Cultural Property-Test Methods-Determination of Water Absorption by Capillarity; CEN (European Committee for Standardization): Brussels, Belgium, 2009.

44. Chatzigrigoriou, A.; Manoudis, P.N.; Karapanagiotis, I. Fabrication of water repellent coatings using waterborne resins for the protection of the cultural heritage. Macromol. Symp. 2013, 331-332, 158-165. [CrossRef]

45. Pargoletti, E.; Motta, L.; Comite, V.; Fermo, P.; Cappelletti, G. The hydrophobicity modulation of glass and marble materials by different si-based coatings. Prog. Org. Coat. 2019, 136, 105260. [CrossRef]

46. Esposito Corcione, C.; De Simone, N.; Santarelli, M.L.; Frigione, M. Protective properties and durability characteristics of experimental and commercial organic coatings for the preservation of porous stone. Prog. Org. Coat. 2017, 103, 193-203. [CrossRef]

47. Calia, A.; Lettieri, M.; Quarta, G.; Laurenzi Tabasso, M.; Mecchi, A. Documentation and assessment of the most important conservation treatments carried out on lecce stone monuments in the last two decades. In Proceedings of the 10th International Congress on Deterioration and Conservation of Stone, Stockholm, Sweden, 27 June-2 July 2004; Kwiatkowski, D., Lofvendahl, R., Eds.; ICOMOS: Stockholm, Sweden, 2004; Volume 1, pp. 431-438.

48. Mosquera, M.J.; Pozo, J.; Esquivias, L. Stress during drying of two stone consolidants applied in monumental conservation. J. Sol Gel Sci. Technol. 2003, 26, 1227-1231. [CrossRef]

49. Aslanidou, D.; Karapanagiotis, I.; Panayiotou, C. Tuning the wetting properties of siloxane-nanoparticle coatings to induce superhydrophobicity and superoleophobicity for stone protection. Mater. Des. 2016, 108, 736-744. [CrossRef]

50. Krzemień, L.; Łukomski, M.; Bratasz, Ł.; Kozłowski, R.; Mecklenburg, M.F. Mechanism of craquelure pattern formation on panel paintings. Stud. Conserv. 2016, 61, 324-330. [CrossRef]

51. Atkinson, A.; Guppy, R.M. Mechanical stability of sol-gel films. J. Mater. Sci. 1991, 26, 3869-3873. [CrossRef]

52. Doehne, E.; Price, C.A. Stone Conservation: An Overview of Current Research; Research in Conservation, 2nd ed.; Getty Conservation Institute: Los Angeles, CA, USA, 2010; ISBN 978-1-60606-046-9.

53. Snethlage, R.; Sterflinger, K. Stone conservation. In Stone in Architecture; Springer: Berlin/Heidelberg, Germany, $2011 ;$ pp. 411-544.

54. Bergamonti, L.; Alfieri, I.; Franzò, M.; Lorenzi, A.; Montenero, A.; Predieri, G.; Raganato, M.; Calia, A.; Lazzarini, L.; Bersani, D.; et al. Synthesis and characterization of nanocrystalline $\mathrm{TiO}_{2}$ with application as photoactive coating on stones. Environ. Sci. Pollut. Res. 2014, 21, 13264-13277. [CrossRef] [PubMed]

55. Vasanelli, E.; Calia, A.; Masieri, M.; Baldi, G. Stone consolidation with $\mathrm{SiO}_{2}$ nanoparticles: Effects on a high porosity limestone. Constr. Build. Mater. 2019, 219, 154-163. [CrossRef]

56. Di Tullio, V.; Proietti, N.; Capitani, D.; Nicolini, I.; Mecchi, A.M. NMR depth profiles as a non-invasive analytical tool to probe the penetration depth of hydrophobic treatments and inhomogeneities in treated porous stones. Anal. Bioanal. Chem. 2011, 400, 3151-3164. [CrossRef]

57. Scrivano, S.; Gaggero, L. Non-Invasive analytical technique to address water uptake on stone surfaces: The implemented contact sponge method (i-CSM). J. Cult. Herit. 2017, 28, 9-15. [CrossRef]

58. Rodrigues, J.D.; Grossi, A. Indicators and ratings for the compatibility assessment of conservation actions. J. Cult. Herit. 2007, 8, 32-43. [CrossRef]

59. Becherini, F.; Pastorelli, G.; Valotto, G.; Gambirasi, A.; Bianchin, S.; Favaro, M. Effects of protective treatments on particle deposition and colour variation in stone surfaces exposed to an urban environment. Prog. Org. Coat. 2017, 112, 75-85. [CrossRef]

60. Colangiuli, D.; Lettieri, M.; Masieri, M.; Calia, A. Field study in an urban environment of simultaneous self-cleaning and hydrophobic nanosized $\mathrm{TiO}_{2}$-based coatings on stone for the protection of building surface. Sci. Total Environ. 2019, 650, 2919-2930. [CrossRef] [PubMed]

61. Licchelli, M.; Marzolla, S.; Carò, F.; Moggi, G. Stone surface protection by fluoropolymers from decay caused by mural writings. Struct. Anal. Hist. Constr. Ed. Paulo B. Lourenco Pere Roca Claudio Modena Shailesh Agrawal MacMillan India Ltd Delhi 2006, $1405-1412$.

62. Sabatini, V.; Pargoletti, E.; Comite, V.; Ortenzi, M.A.; Fermo, P.; Gulotta, D.; Cappelletti, G. Towards novel fluorinated methacrylic coatings for cultural heritage: A combined polymers and surfaces chemistry study. Polymers 2019, 11, 1190. [CrossRef] [PubMed] 